throughout the book. The layout of the chapters and the concise index enable rapid selection of model examples to use in clinical practice. Inclusion of recurrence risks in chromosomal anomalies and the viability of unbalanced re-arrangements improve the usefulness of this wellpriced book. Young has included mention of variable expression and incomplete penetrance as well as the newer issues of gonadal mosaicism, imprinting and the use of mutation detection for carrier-screening in cystic fibrosis. He has included useful tables to help short-cut risk estimations in some common situations.

The book is efficiently referenced and I could find just one error, in table 5.5. My only criticism of the book is that no greater mention is made of the use of computer programmes for tackling the more complex risk estimations. This may have been beyond the scope of the book, but after reading it one ought to be ready for this. Although not of direct relevance to medical ethics, it would be unethical to offer modern genetic counselling without being very familiar with the contents of this book.

IAN H ELLIS

Research Registrar in Genetics, Department of Medical and Molecular Genetics, Guy's Hospital, London SE1 9RT.

\section{Created from animals: the moral implications of Darwinism}

James Rachels, 245 pages, Oxford, 1991, Oxford University Press, £6.99

In choosing to examine the moral implications of 'Darwinism' rather than the moral implications of 'evolution' generally, Rachels makes apparent his affinity for and debt to Darwin's own ideas about evolutionary forces and their relation to human values. While Rachels does not abstain from acknowledging Darwin's errors or miscalculations where appropriate, he does develop his argument from specifically Darwinian claims, with the result that the book differs in at least one significant aspect from many previous attempts to consider morality in the right of evolution. Like Darwin,
Rachels contends that adaptation to environment is not directed to any particular end. Assertions about 'more evolved' and 'less evolved' species, or the 'tendency' of nature to move towards 'higher forms', therefore, cannot be defended. This calls into question assumptions about human values based on our 'higher' standing among other animal groups. If we accept Darwinism, argues Rachels, then traditional Western morality, inspired and bound by beliefs about human dignity, must be rejected or revised. Since medical ethics itself relies in part upon theoretical frameworks within traditional morality, Rachels's argument poses a challenge to clinical medical practice, as well as to medical research in general.

It is to Rachels's credit that he takes pains to confront, explicate and ultimately avoid the logical trap of deriving value from fact, or moral prescriptions from scientific descriptions about the world. Scientific information, rather than strictly entailing moral imperatives, provides reasons for accepting or rejecting a certain theory or belief. Rachels seeks to demonstrate that our traditional belief in human dignity rests upon one, or the other, or both of two major theses; and that if these theses can be undermined by facts about evolutionary biology, then so can the belief about human dignity. The theses are that humans are made in the image of God and that human beings are uniquely rational. For Rachels, discrediting them reveals the frailty of human dignity, a frailty which weakens both the value we place on all human lives and the centrality of human concerns within the wider biological community.

Created from animals offers a lucid, cogent and disciplined argument for a particular perspective on morals. Its focused and detailed pursuit of a few prominent points constitutes its strength. Early chapters on Darwin and on the potential effect of science on ethics are witty and informative. The later chapters introduce and develop Rachels's own theory and these too provide an engaging perspective on ethical and scientific practice.

However, Rachels's claims in relation to the 'human beings are uniquely rational' thesis may be contentious. In this chapter Rachels draws on research about and involving animals to support his claim that a capacity for rationality, once thought to be the province of human beings, can also be attributed to other animals. The difference between human beings and other animals based on rationality thus becomes a difference of degree rather than of kind, making suspect the predication of dignity to humans alone. Rachels quite rightly notes that the entire field of experimental psychology assumes a continuity between humans and other animals by relying on animal subjects to furnish information about human behaviour. What is questionable is not Rachels's attribution of rationality to animals (though some readers will want to dispute its continuity with human rationality) but rather his documentation of the scientific evidence for it.

For example, in suggesting that rhesus monkeys display altruism, Rachels refers to an experiment published in 1964. In another case, he highlights the general intelligence of rhesus monkeys by citing their ability to solve problems not unlike those found on standardised intelligence tests for humans. This is fine, except that the source of this allegation is an experiment reported in 1965. Rachels's claims about a continuity between human and animal rationality would be more convincing if buttressed by recent scientific research. As it stands, he does not include references to current work in the major journals, which leaves one wondering whether or not the results invoked by Rachels have been confirmed or denied during the last twenty or thirty years.

Still, Rachels argues well for his own theory of 'moral individualism', which privileges individual characteristics over species membership in determining moral considerability. In calling for a new principle of equality, Rachels provides an account of relevant differences which determines when we can and cannot distinguish between humans and animals. While he does not approach his topic in the spirit of applied philosophy, Rachels offers a theory which extenuates the belief in human dignity that underlies morality and medical practice. Many will be uncomfortable with his conclusions about the decreased value of human life (discussed partly in terms of euthanasia, suicide and right-tolife) and the increased value of animals. Nevertheless, Rachels's book is a formidable challenge to the doctrine of human dignity. It will now be up to the doctrine's defenders to re-establish, if at all possible, a more 
solid scientific and philosophical footing for its support.

CHERYL FOSTER Assistant Professor, University of Rhode Island, USA.

\section{The Nuffield video library in medical ethics and law}

Produced and directed by Len Doyal. Available to health care institutions (limited number available) from Len Doyal, The London Hospital Medical College, Turner Street, London E1 2AD, £100.00

Anyone who has tried to make videotape recordings for use in teaching medical ethics will appreciate Len Doyal's achievement. The Nuffield Video Library in Medical Ethics and Law consists of six tapes, each containing about 45 minutes of wellstructured and relevant material. A handbook of useful reprinted articles is also included.

The tapes are dedicated to the memory of John Dawson who died at a tragically young age. John Dawson made a tremendous contribution to practical medical ethics in Britain. His clear-headed enthusiasm was a support and stimulus to many of us working in this field. I found it both a sadness and a pleasure to see him on the third of these tapes performing with his characteristic energy.

Each tape is a five-course meal. The starter is an introduction to the topic given by Len Doyal himself. The entrée is a case presentation in which a senior clinician describes a particular patient whose care raised ethical problems relevant to the theme of the tape. The main course, the clinical perspective, is an interview between Len Doyal and an experienced doctor in which some of the theoretical issues raised in the introduction are looked at in more detail. The pudding is a role-play of an interview between doctor and patient, and the meal ends with a brief summary and conclusion.

The tapes as a whole represent the menus for a week; assuming the restaurant staff have an evening off. The topics of the six tapes are as follows: informed consent and good medicine; telling the truth and good medicine; confidentiality and good hospital medicine; informed consent and good psychiatry; and informed consent and good general practice. The assumption is that good medical practice requires a sensitivity to, and an ability to think about, the ethical aspects of medicine; this is an assumption with which few of the readers of this journal will disagree. On the whole Dr Doyal is more concerned to raise ethical issues and to identify the main principles involved than to promote a particular ethical viewpoint. No sustained discussion of medical ethics, however, can be ethically neutral and these tapes present the prevailing perspective in medical ethics (if not the prevailing practice): that it is patients' autonomy which is of prime importance. The choice of topics shows a central concern with what might be broadly considered the doctor-patient relationship: the focus is on consent, confidentiality and truth-telling.

The first thing to be said about these tapes is that they are interesting. The interviews with, for example, Anthony Clare or John Dawson are simply fun to watch; and some of the role-play scenes are gripping. Their value however, stands or falls with their merit as aids to teaching. Each tape is designed to form a unit which can, in theory, be watched from start to finish with suitable pauses for discussion. I doubt, however, whether many teachers of medical ethics will want to use the tapes in this way. I find that video material is most effective in seminar teaching when it is fairly short and when it is only a part of the teaching session. I serve the courses, rather than the meals, to my students. In a seminar on consent, for example, which I run with first-year clinical medical students while they are working on the surgical wards, I have used two sections of the first tape. On some occasions I have chosen the role-play which involves a surgeon trying to persuade a woman to have a mastectomy rather than a 'lumpectomy'. This acts as a stimulating starting point to the seminar and leads students directly into thinking about models of the doctorpatient relationship and what the different models mean in practice. The other part of this tape which I have used is the interview with the surgeon, $\mathrm{Mr}$ John Cochrane. Essentially $\mathrm{Mr}$ Cochrane argues for the importance of obtaining informed consent prior to surgery from both ethical and legal standpoints. In addition he proposes a simple structure for thinking about the risks of surgery: the risks of any operation involving a general anaesthetic; the special risks of this particular operation, and the alternative treatments. Simple though this is it provides medical students with a way of organising their thoughts. The value, I find, in showing the video is that the main message, the importance of taking informed consent seriously, comes from $\mathrm{Mr}$ Cochrane. This is important because a central problem in teaching ethics to medical students is that it is those students who engage least with such teaching who need it most. When I, a psychiatrist with a special interest in ethics, stress to such students the importance of informed consent it is easy for them to ignore my message. But when a senior and successful surgeon, who looks like a senior and successful surgeon, gives the message it has more impact. With thirty 'courses' to choose from, teachers of health care ethics will find that these tapes contain much of value for their seminar teaching.

TONY HOPE

Leader, Oxford Practice Skills Project, Oxford University Medical School, Oxford and Editorial Associate, Journal of Medical Ethics.

\section{Philosophical ethics in reproductive medicine}

Edited by David R Bromham,

Maureen E Dalton and Jennifer C Jackson, Manchester, Manchester University Press, 1990, 261 pages, $£ 40.00$

This book comprises the proceedings of the First International Conference on Philosophical Ethics in Reproductive Medicine (PERM) held at the University of Leeds in April 1988. The main lectures of this conference are grouped in six parts, equivalent to the conference sessions: the embryo; society and assisted conception; the neonate; termination of pregnancy; clinical trials in obstetrics, and informed consent. Each part concludes with a representation of the discussion following the delivery of the papers.

Of the twenty-two contributors, just under half are from the medical professions, the remaining half comprising professional philosophers, theologians, lawyers, and academics involved in the general field of medical 